\title{
The Conditional Relation between Beta and Returns
}

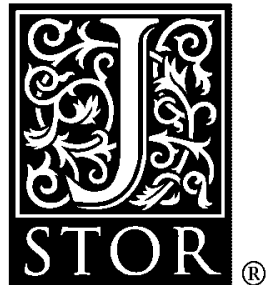

Glenn N. Pettengill; Sridhar Sundaram; Ike Mathur

The Journal of Financial and Quantitative Analysis, Vol. 30, No. 1 (Mar., 1995), 101-116.

Stable URL:

http://links.jstor.org/sici?sici=0022-1090\%28199503\%2930\%3A1\%3C101\%3ATCRBBA\%3E2.0.CO\%3B2-B

The Journal of Financial and Quantitative Analysis is currently published by University of Washington School of Business Administration.

Your use of the JSTOR archive indicates your acceptance of JSTOR's Terms and Conditions of Use, available at http://www.jstor.org/about/terms.html. JSTOR's Terms and Conditions of Use provides, in part, that unless you have obtained prior permission, you may not download an entire issue of a journal or multiple copies of articles, and you may use content in the JSTOR archive only for your personal, non-commercial use.

Please contact the publisher regarding any further use of this work. Publisher contact information may be obtained at http://www.jstor.org/journals/uwash.html.

Each copy of any part of a JSTOR transmission must contain the same copyright notice that appears on the screen or printed page of such transmission.

JSTOR is an independent not-for-profit organization dedicated to creating and preserving a digital archive of scholarly journals. For more information regarding JSTOR, please contact support@ jstor.org. 


\title{
The Conditional Relation between Beta and Returns
}

\author{
Glenn N. Pettengill, Sridhar Sundaram, and Ike Mathur*
}

\begin{abstract}
Unlike previous studies, this paper finds a consistent and highly significant relationship between beta and cross-sectional portfolio returns. The key distinction between our tests and previous tests is the recognition that the positive relationship between returns and beta predicted by the Sharpe-Lintner-Black model is based on expected rather than realized returns. In periods where excess market returns are negative, an inverse relationship between beta and portfolio returns should exist. When we adjust for the expectations concerning negative market excess returns, we find a consistent and significant relationship between beta and returns for the entire sample, for subsample periods, and for data divided by months in a year. Separately, we find support for a positive payment for beta risk.
\end{abstract}

\section{Introduction}

The Sharpe-Lintner-Black (SLB) model, which is predicated on the assumption of a positive risk-return tradeoff, asserts that the expected return for any asset is a positive function of only three variables: beta (the covariance of asset return and market return), the risk-free rate, and the expected market return. This assertion implies that an asset's responsiveness to general market movements is the only variable to cause systematic differences in returns between assets.

Empirical tests of this assertion, using average realized returns to proxy for expected returns and an index of equity security returns as a proxy for market returns, initially supported the validity of the SLB model (e.g., Fama and MacBeth (1973)). The usefulness of beta as the single measure of risk for a security has, however, been challenged by at least three arguments. First, research has challenged the notion that beta is the most efficient measure of systematic risk for individual securities. Thus, some researchers have argued in favor of measuring systematic responsiveness to several macroeconomic variables (e.g., Chen, Roll,

*Pettengill and Sundaram, School of Business, Emporia State University, Emporia, KS 668015087; Mathur, College of Business and Administration, Southern Illinois University at Carbondale, Carbondale, IL 62901, respectively. The authors thank Marcia Cornett, Dave Davidson, John Doukas, Roger Huang, Santosh Mohan, Jim Musumeci, Lilian Ng, Edgar Norton, Nanda Rangan, Andy Szakmary, participants of the Southwest Finance Symposium at the University of Tulsa, JFQA Managing Editor Jonathan Karpoff, and JFQA Referees Michael Pinegar and Alan Shapiro for helpful comments on earlier drafts of the paper. The authors also thank Shari Garnett and Pauletta Avery for their assistance in preparing the manuscript. 
and Ross (1986)). Second, other researchers have found empirical evidence that security returns are affected by various measures of unsystematic risk (e.g., Lakonishok and Shapiro (1986)). Finally, some researchers assert that recent empirical evidence indicates the absence of a systematic relationship between beta and security returns (e.g., Fama and French (1992)). Collectively, the first two criticisms suggest that beta lacks efficiency and completeness as a measure of risk. The third criticism implies either that there is no risk-return tradeoff or that beta does not measure risk. ${ }^{1}$

Despite this evidence against the SLB model, Fama ((1991), p. 1593) asserts that "... market professionals (and academics) still think about risk in terms of market $\beta$." This preference for beta presumably results from the convenience of using a single factor to measure risk and the intuitive appeal of beta. Are these advantages sufficient to justify the continued use of beta if the criticisms cited above are valid? The use of beta may be justified as a measure of risk, even if beta is less efficient than alternative measures of systematic risk or is an incomplete measure of risk. However, if there is no systematic relationship between cross-sectional returns and beta, continued reliance on beta as a measure of risk is inappropriate.

This paper examines the crucial assertion that beta has no systematic relationship with returns. Unlike previous studies, this study explicitly recognizes the impact of using realized market returns to proxy for expected market returns. As developed in the next section, when realized market returns fall below the risk-free rate, an inverse relationship is predicted between realized returns and beta. Acknowledging this relationship leads to the finding of a significant and systematic relationship between beta and returns. Further, evidence of a positive risk-return tradeoff is found when beta is used to measure risk. These results cannot be taken as direct support of the SLB model, but they are consistent with the implication that beta is a useful measure of risk.

In the following section, we discuss the predicted relationship between beta and return distributions for both expected returns and realized returns. Section III reviews previous tests of the relationship between beta and returns. In Section IV, the data and methodology used to test the relationship between beta and realized returns are described. Section V reports empirical results that show a systematic relationship between returns and beta and support for a positive risk-return tradeoff. Section VI concludes the paper.

\section{Beta and Returns: The SLB Model and Empirical Tests}

\section{A. Model Implications}

The SLB model asserts that investors are rewarded only for systematic risk since unsystematic risk can be eliminated through diversification. Thus, the security market line specifies that the expected return to any risky security or portfolio of risky securities is the sum of the risk-free rate and a risk premium determined

\footnotetext{
${ }^{1}$ Roll and Ross (1994) attribute the observed lack of a systematic relation between risk and return to the possible mean-variance inefficiency of the market portfolio proxies.
} 
by beta. Tests of this assertion examine portfolios of securities to reduce both estimation error and nonsystematic risk. The relationship tested is represented as

$$
E\left(R_{p}\right)=R_{f}+\beta_{p} *\left(E\left(R_{m}\right)-R_{f}\right),
$$

where $E\left(R_{p}\right)$ is the expected return for the risky portfolio $p, R_{f}$ is the current risk-free rate, $\beta_{p}$ is the covariance between the portfolio's return and the market's return divided by the variance of the market, and $E\left(R_{m}\right)$ is the expected return to the market.

The interrelationship between these variables provides crucial implications for testing the relationship between beta and returns. On the assumption of a positive risk-return tradeoff, the expected return to the market must be greater than the risk-free return (or all investors would hold the risk-free security). Since the term $\left(E\left(R_{m}\right)-R_{f}\right)$ must be positive, the expected return to any risky portfolio is a positive function of beta. This relationship has prompted researchers to examine the validity of the SLB by testing for a positive relationship between returns and beta. Since these tests use realized returns instead of expected returns, we argue that the validity of the SLB model is not directly examined. Indeed, recognition of a second critical relationship between the predicted market returns and the riskfree return suggests that previous tests of the relationship between beta and returns must be modified.

The need to modify previous tests results from the model's requirement that a portion of the market return distribution be below the risk-free rate. In addition to the expectation that, on average, the market return be greater than the risk-free rate, investors must perceive a nonzero probability that the realized market return will be less than the risk-free return. If investors were certain that the market return would always be greater than the risk-free rate, no investor would hold the risk-free security. This second requirement suggests that the relationship between beta and realized returns varies from the relationship between beta and expected return required by Equation (1). However, the model does not provide a direct indication of the relationship between portfolio beta and portfolio returns when the realized market return is less than the risk-free return. A further examination, as detailed below, shows that an inverse relationship between beta and returns can be reasonably inferred during such periods.

In order to draw this inference, it is necessary to provide an analysis of the portfolio return distribution implied by the SLB model. This model shows that the expected return for each portfolio is a function of the risk-free return, the portfolio beta, and the expected return to the market. The expected return for the portfolio is the mean of the distribution for all possible returns for that portfolio in the appropriate return period. Identical with the market return, for all portfolios with a positive beta, the expected value for the return distribution must be greater than the risk-free rate and the return distribution must contain a non-zero probability of realizing a return below the risk-free rate. To arrive at testable implications, we must extend this analysis to examine the differences in the return distributions of portfolios with different betas.

Portfolios with higher betas have higher expected returns because of higher risks. For high beta portfolios to have higher risk, there must be some level of realized return for which the probability of exceeding that particular return is 
greater for the low beta portfolio than for the high beta portfolio. If this were not the case, no investor would hold the low beta portfolio. Thus, the SLB model not only requires the expectation that realized returns for the market will, with some probability, be lower than the risk-free rate, but also requires the expectation that, with some probability, the realized returns for high beta portfolios will be lower than the realized returns for low beta portfolios. The model does not require a direct link between these two relationships. A reasonable inference may, however, be that returns for high beta portfolios are less than returns for low beta portfolios when the realized market return is less than the risk-free rate. Although previous tests of the SLB model have not recognized these relationships when testing the validity of the SLB model, the market model used to calculate beta does imply this relationship.

\section{B. Empirical Tests}

Previous tests of the implications of the SLB model have sought to find a positive relationship between realized portfolio returns and portfolio betas. The tests are conducted in stages, with the estimation of beta as shown below,

$$
\left(R_{p t}-R_{f t}\right)=\hat{\beta}_{p} *\left(R_{m t}-R_{f t}\right)+\epsilon_{p t},
$$

followed by the test for a positive risk-return tradeoff,

$$
R_{p t}=\hat{\gamma}_{0}+\hat{\gamma}_{1} * \beta_{p}+\epsilon_{t}
$$

Equation (2) estimates the beta risk for each portfolio using realized returns for both the portfolio and the market, thus providing a proxy for the beta in the SLB model. Under the assumption that betas in the estimation period proxy betas in the test period, a test for a positive risk-return relationship utilizes Equation (3). If the value for $\hat{\gamma}_{1}$ is greater than zero, a positive risk-return tradeoff is supported. This procedure may test the usefulness of beta as a measure of risk, but it does not directly test the validity of the SLB model.

The SLB model not only requires a direct and unconditional relationship between beta and expected returns, but also requires the expectation that the relationship between realized returns and beta will vary. As argued in the previous section, in order for high beta portfolios to have more risk, there must be conditions under which high beta portfolios earn lower returns than low beta portfolios. The SLB model does not directly provide the conditions under which the above relationship will be observed. In contrast, Equation (2), which has been used in previous empirical tests, provides an exact condition under which the realized returns to high beta portfolios are expected to be lower than the realized returns for low beta portfolios. According to Equation (2), the relationship between the return to high and low beta portfolios is conditional on the relationship between realized market returns and the risk-free return. If $R_{m}<R_{f}$, then $\beta_{p} *\left(R_{m t}-R_{f t}\right)$ is $<0$. In these cases, the predicted portfolio return includes a negative risk premium that is proportionate to beta. Hence, if the realized market return is less than the risk-free return, an inverse relationship exists between beta and predicted return (i.e., high beta portfolios have predicted returns that are less than the predicted returns for 
low beta portfolios). This relationship provides important implications concerning empirical tests for a systematic relationship between beta and returns.

A systematic relationship must exist between beta and returns for beta to be a useful measure of risk. The SLB model prescribes a systematic and positive tradeoff between beta and expected return, but the above discussion reflects a segmented relationship between realized returns and beta, i.e., a positive relation during positive market excess return periods and a negative relation during negative market excess return periods. If realized market returns were seldom less than the risk-free rate, this conditional relationship would have a trivial impact on tests of the relationship between beta and returns. This relationship, however, occurs frequently. A month-by-month comparison of the CRSP equally-weighted index (as the proxy for market return) and the 90-day T-bill rate (as the measure for the risk-free return) over the period 1936 through 1990 reveals that the Tbill rate exceeds the market return in 280 out of 660 total observations. The existence of a large number of negative market excess return periods suggests that previous studies that test for an unconditional positive correlation between beta and realized returns are biased against finding a systematic relationship. This paper employs testing procedures that account for the segmented relationship and finds a significant impact of beta on returns.

\section{Previous Tests of the Relationship between Beta and Returns}

Extant literature examining the relationship between beta and returns has primarily tested for a positive linear relationship as prescribed by the SLB model. Although the model postulates a positive tradeoff between risk (beta) and expected return, prior studies have examined the realized returns of equity portfolios formed from rankings of betas. They generally find a weak, but positive, relationship between returns and beta over the entire sample period, but these results are often found to be intertemporally inconsistent and weaker than the association between returns and other variables (e.g., size). These results are generally interpreted as evidence against the validity of a positive relationship between beta and returns. The findings of the major studies in this area are briefly described here.

Fama and MacBeth's (1973) seminal study on the validity of the SLB model takes a three-step approach. In the first step, portfolios are formed based on estimated beta for individual securities. The second step involves estimation of each portfolio's beta in a subsequent time period. In the final step, using data from a third time period, portfolio returns are regressed on portfolio betas. Since, on average, for the period 1935 through 1968, a positive relationship exists between beta and monthly returns, Fama and MacBeth conclude that the SLB model adequately describes the risk-return behavior observed in capital markets. Schwert (1983), however, suggests that this evidence provides surprisingly weak support for a risk-return tradeoff.

Following Fama and MacBeth, a number of researchers have conducted empirical analyses that suggest that beta may not adequately measure a security's risk. Reinganum (1981) finds that "... estimated betas are not systematically related to average returns across securities" and concludes "... that the SLB model may lack 
significant empirical content" (p. 439). In a sample of daily returns, Reinganum finds a tendency for portfolio returns to decrease as beta increases. In contrast, for a sample of monthly returns, Reinganum finds a positive relationship between returns and beta, but argues that this apparent corroboration is spurious on two counts. First, the difference in returns across portfolios is not significant. Second, the positive relationship between beta risk and return is not consistent across subperiods. $^{2}$

Tinic and West (1984) also reject the validity of the SLB model based on intertemporal inconsistencies. Using monthly data, they find a positive and significant slope when regressing portfolio returns on portfolio betas when return data for the entire year are included. Tinic and West are, however, unable to reject the null hypothesis of no difference in returns across portfolios if return data from the month of January are excluded. ${ }^{3}$ Further, for several months of the year, negative slope coefficients are observed. This inconsistent support for the SLB model across months of the year led them to conclude that their results "... cast serious doubt on the validity of the two-parameter model ..." and "... to the extent that the risk-return tradeoff shows up only in January, much of what now constitutes the received version of modern finance is brought into question" (Tinic and West (1984), p. 573).

Several other studies stress that the ability of beta to explain changes in return is weak relative to other variables. Lakonishok and Shapiro (1984), (1986) find an insignificant relationship between beta and returns. Further, Lakonishok and Shapiro find a significant relationship between returns and market capitalization values. From these tests, Lakonishok and Shapiro conclude that an “... individual security's return did not appear to be specifically related to its degree of systematic risk" ((1984), p. 36).

Fama and French (1992) study monthly returns and find an insignificant relationship between beta and average returns. In contrast, market capitalization and the ratio of book value to market value have significant explanatory power for portfolio returns. Fama and French state: "We are forced to conclude that the SLB model does not describe the last 50 years of average stock returns" (p. 464).

In summary, Reinganum finds the relationship between beta and cross-sectional returns to vary across subperiods. Tinic and West find the relationship between beta and the returns to vary with months in a year. Lakonishok and Shapiro and Fama and French find the relationship between beta and returns to be weaker than the relationship between returns and other variables. Collectively, these results have been taken as evidence that the SLB model provides an inadequate explanation for the risk-return behavior observed in capital markets. In contrast, the methodology described below accounts for the conditional relationship between beta and realized returns, and finds a systematic relationship between these variables.

\footnotetext{
${ }^{2}$ Although they argue in support of the SLB model, Fama and MacBeth find similar inconsistency among subperiods.

${ }^{3}$ This result is consistent with Rozeff and Kinney (1976), who find the risk premium for January to be higher than for other months.
} 


\section{Data and Methodology}

\section{A. Data}

The sample period for this study extends from January 1926 through December 1990. Monthly returns for the securities included in the sample and the CRSP equally-weighted index ${ }^{4}$ (as a proxy for the market index) were obtained from the CRSP monthly databases. The three-month Treasury bill rates (a proxy for the risk-free rate) for the period 1936 through 1990 were collected from the Federal Reserve Bulletin.

\section{B. Test of a Systematic Relationship between Beta and Returns}

The purpose of this paper is twofold. The first is to test for a systematic, conditional relationship between betas and realized returns. The second is to test for a positive long-run tradeoff between beta risk and return.

Tests for a systematic relationship utilize a modified version of the three-step portfolio approach first used by Fama and MacBeth (1973). The sample period is first separated into 15-year subperiods, which are further divided into a portfolio formation period, a portfolio beta estimation period, and a test period of five years each. In the portfolio formation period, betas are estimated for each security in the sample by regressing the security's return against the market return. Based on the relative rankings of the estimated beta, securities are equally divided into 20 portfolios. Securities with lowest betas are placed in the first portfolio, the next lowest in the second portfolio, and so on. Portfolio betas are estimated in the second five-year period within each subsample by regressing portfolio returns (the equally-weighted return of all securities in the portfolio) against the market returns.

The third step, which tests the relationship between portfolio beta and returns, is modified to account for the conditional relationship between beta and realized returns. As argued in Section II, if the realized market return is above the risk-free return, portfolio betas and returns should be positively related, but if the realized market return is below the risk-free return, portfolio betas and returns should be inversely related. Hence, to test for a systematic relationship between beta and returns, the regression coefficients from Equation (4) are examined,

$$
R_{i t}=\hat{\gamma}_{0 t}+\hat{\gamma}_{1 t} * \delta * \beta_{i}+\hat{\gamma}_{2 t} *(1-\delta) * \beta_{i}+\epsilon_{t},
$$

where $\delta=1$, if $\left(R_{m t}-R_{f t}\right)>0$ (i.e., when market excess returns are positive), and $\delta=0$, if $\left(R_{m t}-R_{f t}\right)<0$ (i.e., when market excess returns are negative). The above relationship is examined for each month in the test period by estimating either $\gamma_{1}$ or $\gamma_{2}$, depending on the sign for market excess returns. ${ }^{5}$

Since $\gamma_{1}$ is estimated in periods with positive market excess returns, the expected sign of this coefficient is positive. Hence, the following hypotheses are tested,

\footnotetext{
${ }^{4}$ There is no material difference in the results when the value-weighted index is used.

${ }^{5}$ The division of the entire sample period into up markets and down markets was first performed by Lakonishok and Shapiro (1984).
} 
Ho : $\bar{\gamma}_{1}=0$,

$\mathrm{Ha}: \bar{\gamma}_{1}>0$.

Since $\gamma_{2}$ is estimated in periods with negative market excess returns, the expected sign of this coefficient is negative. Hence, the following hypotheses are tested,

Ho : $\bar{\gamma}_{2}=0$,

Ha : $\bar{\gamma}_{2}<0$.

A systematic conditional relationship between beta and realized returns is supported if, in both cases, the null hypothesis is rejected in favor of the alternate.

\section{Subsample Procedures}

The sample period of 1926 through 1990 allows for the creation of 11 distinct 15-year subsamples. The first subsample extends from 1926 through 1940, the second from 1931 through 1945 , and so on. In the first subsample, the first fiveyear period (1926-1930) is the portfolio formation period, the second (19311935) and third (1936-1940) five-year periods are the portfolio beta estimation period and the test period, respectively. Each subsample includes all securities available from the CRSP monthly returns file that have at least 45 observations in each of the three periods within the subsample. The number of securities in the 11 subsamples ranged from a low of 366 (first subsample) to a high of 1350 (penultimate subsample). The entire three-step procedure is conducted separately for each subperiod.

Equation (4) is first examined using all 660 monthly observations. In addition, the data are divided into three approximately equal subperiods: 1936 through 1950 , 1951 through 1970, and 1971 through 1990. Separately, the data are divided by months in a year. Applying Equation (4) to each of these subperiods tests whether intertemporal inconsistencies and seasonality observed by previous studies result from the conditional nature of the relationship between beta and realized returns.

\section{A Test of the Positive Risk-Return Tradeoff}

The second goal of the study is to determine if a systematic relationship between beta and return translates into a positive reward for holding risk (i.e., do high beta assets, on average, earn higher returns than low beta assets?). If a systematic, conditional relationship between beta risk and returns exists, a positive reward for holding beta risk will occur if two conditions are met: i) market excess returns are, on average, positive; and ii) the risk-return relationship is symmetrical between periods of positive and negative excess market returns. We test each of these conditions and then provide a direct test of a positive risk-return tradeoff.

The average market excess return for the total sample period and the various subperiods are calculated to test for the first condition. A standard $t$-test is used to determine if market excess returns are, on average, positive. The risk premiums during up and down markets, as captured by $\hat{\gamma}_{1}$ and $\hat{\gamma}_{2}$, are compared to test for symmetry. Since the expected signs of these coefficients differ, a direct comparison of their average values would be inappropriate. To facilitate comparisons, the sign for $\hat{\gamma}_{2}$ is reversed and its mean value is reestimated. These adjustments allow a 
direct comparison while preserving the effects of slope estimates with unexpected signs (i.e., a negative sign for $\hat{\gamma}_{1}$ and a positive sign for $\hat{\gamma}_{2}$ ). After the adjustments, the following hypotheses are tested by using a standard two-population $t$-test,

Ho: $\bar{\gamma}_{1}-\bar{\gamma}_{2}=0$,

$\mathrm{Ha}: \bar{\gamma}_{1}-\bar{\gamma}_{2} \neq 0$.

Finally, a direct test of the risk-return tradeoff is employed by regressing the average portfolio betas against average portfolio returns.

\section{Empirical Results}

\section{A. Beta vs. Realized Returns}

Previous studies, following Fama and MacBeth, test for a positive linear relationship between risk and realized return. For comparative purposes, we examine this relation by estimating the slope coefficients for Equation (3). Results for the total sample period reported in Table 1 reject the hypothesis of no relation between risk and return at the 0.05 level. However, the results are inconsistent across subperiods. The null hypothesis is rejected in the first subperiod at the 0.05 level but the null cannot be rejected in the second $(t=0.18)$ or third $(t=1.30)$ subperiods. Extant literature cites this weak correlation and the intertemporal inconsistency as evidence against a systematic relationship between risk and return.

TABLE 1

Estimates of Slope Coefficients (CRSP Equally-Weighted Index)

$$
R_{i t}=\hat{\gamma}_{0}+\hat{\gamma}_{1} * \beta_{i}+\epsilon_{i t}
$$

\begin{tabular}{lccc}
\hline \multicolumn{1}{c}{ Period } & $\frac{\overline{\hat{\gamma}_{1}}}{n}$ & $\frac{T \text {-Statistic }}{2.23}$ & $\frac{P \text {-Value }}{0.0050}$ \\
$\begin{array}{l}\text { Total Sample } \\
(1936-1990)\end{array}$ & 0.0111 & 2.05 & 0.0129 \\
$\begin{array}{l}\text { Period 1 } \\
(1936-1950)\end{array}$ & 0.0005 & 0.18 & 0.0207 \\
$\begin{array}{l}\text { Period 2 } \\
(1951-1970)\end{array}$ & 0.0005 & 1.30 & 0.4277 \\
$\begin{array}{l}\text { Period 3 } \\
(1971-1990)\end{array}$ & & & 0.0975 \\
\hline
\end{tabular}

We argue that the above results are biased due to the aggregation of positive and negative market excess return periods. Given the conditional relation between risk (beta) and realized returns, we test the dual hypothesis of a positive relation between beta and returns during periods of positive market excess returns and a negative relation during periods of negative market excess returns. The hypothesis is tested by examining the regression coefficients $\hat{\gamma}_{1}$ and $\hat{\gamma}_{2}$ of Equation (4). The regression estimates are presented in Table 2.

Examination of the estimated regression coefficients provides strong support for a systematic but conditional relationship between beta and realized returns. $\gamma_{1}$ is estimated in each of the 380 months for which the market excess return is 
TABLE 2

Estimates of Slope Coefficients for Up Markets and Down Markets (CRSP Equally-Weighted Index)

$$
R_{i t}=\hat{\gamma}_{0}+\hat{\gamma}_{1} * \delta * \beta_{i}+\hat{\gamma}_{2} *(1-\delta) * \beta_{i}+\epsilon_{i t}
$$

\begin{tabular}{|c|c|c|c|c|c|c|}
\hline \multirow[b]{2}{*}{ Period } & \multicolumn{3}{|c|}{ Panel A. Up Markets } & \multicolumn{3}{|c|}{ Panel B. Down Markets } \\
\hline & $\overline{\hat{\gamma}_{1}}$ & $T$-Statistic & $\underline{P \text {-Value }}$ & $\overline{\hat{\gamma}_{2}}$ & T-Statistic & $P$-Value \\
\hline $\begin{array}{l}\text { Total Sample } \\
(1936-1990)\end{array}$ & 0.0336 & 12.61 & 0.0001 & -0.0337 & -13.82 & 0.0001 \\
\hline $\begin{array}{l}\text { Period } 1 \\
(1936-1950)\end{array}$ & 0.0482 & 7.64 & 0.0001 & -0.0431 & -8.70 & 0.0001 \\
\hline $\begin{array}{l}\text { Period } 2 \\
(1951-1970)\end{array}$ & 0.0185 & 6.74 & 0.0001 & -0.0296 & -8.67 & 0.0001 \\
\hline $\begin{array}{l}\text { Period } 3 \\
(1971-1990)\end{array}$ & 0.0392 & 8.23 & 0.0001 & -0.0309 & -7.46 & 0.0001 \\
\hline
\end{tabular}

Up markets (down markets) are periods of positive (negative) market excess returns.

positive. In these periods, the high beta portfolios should outperform the low beta portfolios. This expectation is confirmed by the mean value of 0.0336 for $\hat{\gamma}_{1}$, which is significantly different from zero at the 0.01 level $(t=12.61)$. This result shows that high beta portfolios receive a positive risk premium during up markets. $\gamma_{2}$ is estimated for the 280 months in which market excess return is negative. The expected negative relationship between realized returns and portfolio beta should produce negative values for $\hat{\gamma}_{2}$. The mean value of -0.0337 is significantly different from zero at the 0.01 level $(t=-13.82) .{ }^{6}$ This result shows that, as expected, high beta portfolios incur lower returns during down markets than low beta portfolios. The mean excess returns for portfolios 1 through 20 during up markets (periods of positive market excess return) and down markets (periods of negative market excess return) are shown in Figure 1. With minor variations, the figure provides corroborative evidence on the expected association between beta and portfolio returns.

Table 2 also presents the results for estimates of $\gamma_{1}$ and $\gamma_{2}$ for each of the three subperiods. Unlike previous studies, we find a highly significant relationship between beta and returns in each subperiod. For every subperiod, the hypothesis of no relationship between risk and returns during periods of positive excess market returns is rejected in favor of an expected positive relationship at the 0.01 level. ${ }^{7}$ Likewise, for every subperiod, the hypothesis of no relationship between risk and returns during periods of negative excess market returns is rejected in favor of an expected negative relationship at the 0.01 level. Previous studies that find inconsistent relationships between beta and returns across subperiods do so because they fail to adjust for the conditional relationship between returns and beta.

\footnotetext{
${ }^{6}$ Results from Lakonishok and Shapiro (1984) indicate a similar relationship between beta and returns. They find slope coefficients of 0.0333 and -0.0354 for up markets and down markets, respectively.

${ }^{7}$ Although the estimated coefficients are of the correct sign and significant in each of the subperiods, a significant difference does exist in the estimated values of $\gamma_{1}$ and $\gamma_{2}$ between subperiods.
} 
FIGURE 1

Average Portfolio Return: Positive and Negative Market Excess Return Periods

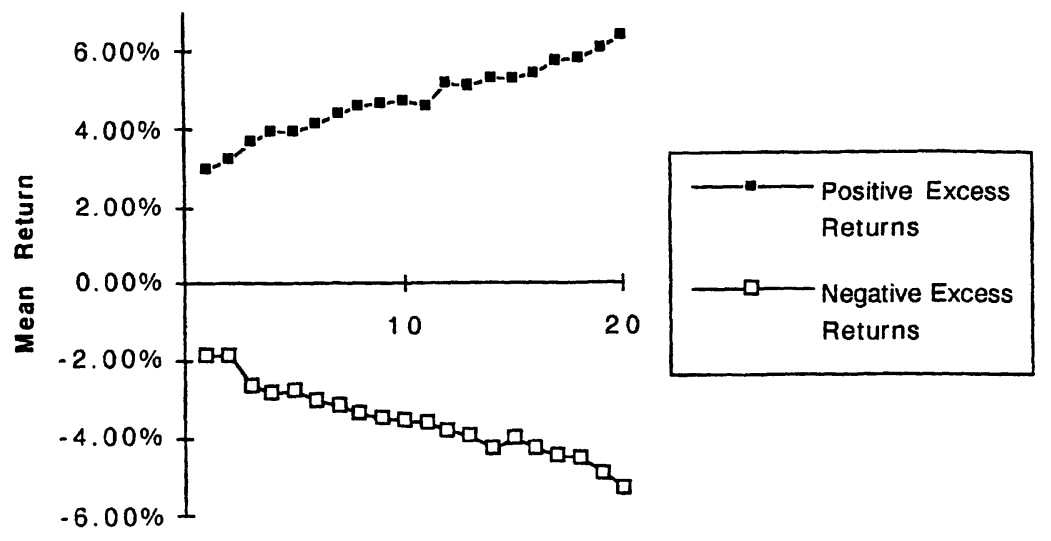

Portfolio

\section{B. Seasonality in Risk-Return Relation}

We test for seasonality in the risk-return relation by segmenting the data by months and reestimating Equations (3) and (4). Table 3 reports the regression coefficients from Equation (3). Examination of these results shows the rejection of the null hypothesis of no risk-return relation only for the months of January $(t=5.13)$ and February $(t=2.23)$. This observed seasonality is consistent with Tinic and West (1984), who find a significant and positive risk-return relation only in the month of January. Further, six out of 12 months report a negative slope coefficient, implying an inconsistent risk-return relation.

This observed inconsistency may be primarily due to the bias from the conditional relation between beta and realized returns. This contention is tested by examining the regression coefficients of Equation (4) with data segmented by months. The results are presented in Table 4 . When market excess returns are positive, a significant positive relationship exists between beta and return for each of the months. The null hypothesis of no risk-return relation is rejected at the 0.01 level for each of the months except June, September, and October (null rejected at the 0.05 level). When market excess returns are negative, a significant negative relation exists between beta and portfolio returns for all months except January $(t=-0.92) .{ }^{8}$ These results firmly support a consistent relation between beta and returns throughout the year when the conditional relationship between beta and realized returns is considered.

\footnotetext{
${ }^{8}$ The insignificant relationship in January may be explained by the small firm effect. Small firms, which, in general, possess higher risk (see Fama and French (1992)), also experience higher returns in January (see Reinganum (1983)), possibly causing high beta portfolios to have relatively high returns even during periods of negative market excess returns.
} 


\section{TABLE 3}

Estimates of Slope Coefficients

(CRSP Equally-Weighted Index)

Total Sample Period: 1936-1990

$$
R_{i t}=\hat{\gamma}_{0}+\hat{\gamma}_{1} * \beta_{i}+\epsilon_{i t}
$$

\begin{tabular}{lrcr}
\hline Period & $\overline{\hat{\gamma}_{1}}$ & $\frac{T \text {-Statistic }}{2}$ & $P$-Value \\
\cline { 2 - 3 } All Months & 0.0050 & 2.23 & 0.0129 \\
January & 0.0461 & 5.13 & 0.0001 \\
February & 0.0164 & 2.23 & 0.0150 \\
March & 0.0058 & 0.79 & 0.2166 \\
April & 0.0071 & 1.00 & 0.1601 \\
May & -0.0046 & -0.79 & 0.7821 \\
June & -0.0009 & -0.13 & 0.5505 \\
July & 0.0091 & 1.11 & 0.1360 \\
August & -0.0037 & -0.07 & 0.7420 \\
September & -0.0012 & -0.12 & 0.5489 \\
October & -0.0154 & -1.71 & 0.9536 \\
November & -0.0016 & -0.23 & 0.5890 \\
December & 0.0033 & 0.50 & 0.3096 \\
\hline
\end{tabular}

\section{TABLE 4}

Estimates of Slope Coefficients for Up Markets and Down Markets (CRSP Equally-Weighted Index)

$$
R_{i t}=\hat{\gamma}_{0}+\hat{\gamma}_{1} * \delta * \beta_{i}+\hat{\gamma}_{2} *(1-\delta) * \beta_{i}+\epsilon_{i t}
$$

\begin{tabular}{|c|c|c|c|c|c|c|}
\hline \multirow[b]{2}{*}{ Period } & \multicolumn{3}{|c|}{ Panel A. Up Markets } & \multicolumn{3}{|c|}{ Panel B. Down Markets } \\
\hline & $\overline{\hat{\gamma}_{1}}$ & T-Statistic & $\underline{P \text {-Value }}$ & $\overline{\hat{\gamma}_{2}}$ & T-Statistic & $P$-Value \\
\hline All Months & 0.0336 & 12.61 & 0.0001 & -0.0337 & -13.82 & 0.0001 \\
\hline January & 0.0670 & 6.79 & 0.0001 & -0.0097 & -0.92 & 0.3715 \\
\hline February & 0.0387 & 4.31 & 0.0001 & -0.0227 & -3.40 & 0.0030 \\
\hline March & 0.0283 & 4.74 & 0.0001 & -0.0306 & -2.27 & 0.0345 \\
\hline April & 0.0344 & 4.66 & 0.0001 & -0.0308 & -3.47 & 0.0022 \\
\hline May & 0.0173 & 2.99 & 0.0054 & -0.0375 & -4.92 & 0.0001 \\
\hline June & 0.0258 & 2.36 & 0.0259 & -0.0286 & -5.12 & 0.0001 \\
\hline July & 0.0421 & 4.25 & 0.0002 & -0.0367 & -5.64 & 0.0001 \\
\hline August & 0.0201 & 2.91 & 0.0069 & -0.0323 & -5.75 & 0.0001 \\
\hline September & 0.0415 & 2.42 & 0.0240 & -0.0342 & -5.31 & 0.0001 \\
\hline October & 0.0231 & 2.36 & 0.0265 & -0.0498 & -4.39 & 0.0001 \\
\hline November & 0.0289 & 3.90 & 0.0005 & -0.0441 & -5.89 & 0.0001 \\
\hline December & 0.0263 & 3.54 & 0.0012 & -0.0338 & -4.43 & 0.0003 \\
\hline
\end{tabular}

Up markets (down markets) are periods of positive (negative) market excess returns.

Results from Tables 2 and 4 show that when the testing procedure is adjusted for the conditional nature of the relation between risk (beta) and realized returns, a significant relationship is found between portfolio beta and mean monthly rates of return for the entire 55-year period. Further, this relationship holds across subperiods and across months in a year, contrary to the inconsistencies observed 
by previous studies. These results support the validity of beta as a measure of risk and its ability to explain the cross-sectional variation in portfolio returns. ${ }^{9}$

\section{Risk vs. Return: A Test for a Positive Tradeoff}

Given the systematic relationship between beta and returns, a positive riskreturn tradeoff requires that i) market excess returns, on average, be positive, and ii) the risk-return relation be consistent during up markets and down markets (i.e., periods of positive and negative market excess returns). The following discussion examines the results from the tests of the above requirements.

To examine if average market excess returns are positive, the mean excess returns for the total sample period and the subperiods are estimated. Table 5 reports an average annualized excess return of 11.45 percent for the total period, rejecting the null hypothesis of zero excess return at the 0.01 level $(t=3.74)$. Results for the subperiods show an average annualized excess return of 18.06 percent $(t=2.35)$ for period 1 , and 11.14 percent $(t=3.02)$ for period 2, rejecting the null hypothesis at the 0.01 level in both cases. The excess return of 7.02 percent $(t=1.41)$ in period 3 allows rejection only at the 10 -percent level of significance. These results indicate a significant positive reward for holding market risk during the overall sample period. However, the risk premium during the subperiods, though positive, appears to be influenced by the general economic conditions during the period examined.

TABLE 5

Average Market Excess Returns for Sample Periods

\begin{tabular}{|c|c|c|c|c|}
\hline & $\begin{array}{c}\text { Total Period } \\
(1936-1990) \\
\end{array}$ & $\begin{array}{c}\text { Period 1 } \\
(1936-1950) \\
\end{array}$ & $\begin{array}{c}\text { Period 2 } \\
(1951-1970) \\
\end{array}$ & $\begin{array}{c}\text { Period } 3 \\
(1971-1990) \\
\end{array}$ \\
\hline $\begin{array}{l}\text { Annualized Mean } \\
\text { Excess Return }\end{array}$ & $11.45 \%$ & $18.06 \%$ & $11.14 \%$ & $7.02 \%$ \\
\hline $\begin{array}{l}\text { Monthly Mean } \\
\text { Excess Return }\end{array}$ & $0.91 \%$ & $1.39 \%$ & $0.88 \%$ & $0.57 \%$ \\
\hline Monthly Variance & 0.0039 & 0.0064 & 0.0021 & 0.0039 \\
\hline $\begin{array}{l}T \text {-Statistic }{ }^{a} \\
P \text {-Value }\end{array}$ & $\begin{array}{l}3.74 \\
0.0002\end{array}$ & $\begin{array}{l}2.35 \\
0.0101\end{array}$ & $\begin{array}{l}3.02 \\
0.0014\end{array}$ & $\begin{array}{l}1.41 \\
0.0796\end{array}$ \\
\hline
\end{tabular}

aThe $t$-statistic measures the null hypothesis that mean excess returns equal zero.

The second condition required for a positive tradeoff is a consistent relation between risk and return during up markets and down markets. This is examined by comparing $\hat{\gamma}_{1}$ and $\hat{\gamma}_{2}$ from Equation (4) for the total sample period. Table 2 reports the mean values of $\hat{\gamma}_{1}(0.0336)$ and $\hat{\gamma}_{2}(-0.0337)$ for the total sample period. Given the expected difference in signs, these values reflect a strong consistency

\footnotetext{
${ }^{9}$ We test for robustness of the results reported in Tables 2 and 4, making two separate modifications in our testing procedures. First, we define a one-factor model as follows: $R_{p}=E\left(R_{p}\right)+\beta_{p} *\left[R_{m}-\right.$ $\left.E\left(R_{m}\right)\right]+\epsilon$. We then regress the unexpected portfolio return against beta with up and down markets determined by whether the market surprise $\left(R_{m}-E\left(R_{m}\right)\right)$ was positive or negative. Second, we estimate portfolio betas separately in up and down market periods (see Wiggins (1992)). We then regress returns against up or down betas depending on the relationship between market return and the risk-free rate. In both cases, results strongly support a significant relationship between beta and returns.
} 
in the relation between beta and returns. A two-population $t$-test (with the sign adjustment for $\hat{\gamma}_{2}$ as described in methodology section) results in a $t$-value of 0.029 , which reflects a symmetrical relation between risk and return during positive and negative periods. This result, combined with the finding of positive average excess returns in each period, strongly supports the expectation of a positive reward for holding risk.

The hypothesis of a positive risk-return relation is further tested by directly examining the association between betas and portfolio returns. The average return and the corresponding beta for each portfolio are reported in Panel A of Table 6. The reported return is the average from the 660 monthly return observations. The portfolio betas are the average of the betas for each of the 11 subperiods. The average betas for portfolio 1 (lowest risk) and portfolio 20 (highest risk) are found to be 0.49 and 1.50 , respectively. Their corresponding average annualized returns are 11.82 percent (portfolio 1) and 18.97 percent (portfolio 20).

\section{TABLE 6}

Test of Risk-Return Tradeoff: Results from Regressing Average Portfolio Beta on Annualized Average Returns

$$
R_{p}=\gamma_{0}+\gamma_{1} * \beta p+\epsilon p
$$

\section{Panel A. Average Portfolio Betas and Returns}

\begin{tabular}{|c|c|c|c|c|}
\hline \multicolumn{2}{|l|}{ Portfolio } & $\begin{array}{c}\text { Average } \\
\text { Beta }\end{array}$ & & $\begin{array}{c}\text { Annualized } \\
\text { Average } \\
\text { Return } \\
\end{array}$ \\
\hline \multicolumn{2}{|l|}{1} & 0.49 & & 0.1182 \\
\hline \multicolumn{2}{|l|}{2} & 0.53 & & 0.1349 \\
\hline \multicolumn{2}{|l|}{3} & 0.62 & & 0.1267 \\
\hline \multicolumn{2}{|l|}{4} & 0.67 & & 0.1374 \\
\hline \multicolumn{2}{|l|}{5} & 0.70 & & 0.1417 \\
\hline \multicolumn{2}{|l|}{6} & 0.77 & & 0.1416 \\
\hline \multicolumn{2}{|l|}{7} & 0.83 & & 0.1537 \\
\hline \multicolumn{2}{|l|}{8} & 0.83 & & 0.1532 \\
\hline \multicolumn{2}{|l|}{9} & 0.89 & & 0.1580 \\
\hline \multicolumn{2}{|l|}{10} & 0.91 & & 0.1587 \\
\hline \multicolumn{2}{|l|}{11} & 0.95 & & 0.1440 \\
\hline \multicolumn{2}{|l|}{12} & 0.99 & & 0.1776 \\
\hline \multicolumn{2}{|l|}{13} & 1.04 & & 0.1664 \\
\hline \multicolumn{2}{|l|}{14} & 1.09 & & 0.1605 \\
\hline \multicolumn{2}{|l|}{15} & 1.10 & & 0.1740 \\
\hline \multicolumn{2}{|l|}{16} & 1.17 & & 0.1682 \\
\hline \multicolumn{2}{|l|}{17} & 1.19 & & 0.1843 \\
\hline \multicolumn{2}{|l|}{18} & 1.29 & & 0.1857 \\
\hline \multicolumn{2}{|l|}{19} & 1.36 & & 0.1836 \\
\hline \multicolumn{2}{|l|}{20} & 1.50 & & 0.1897 \\
\hline \multicolumn{5}{|c|}{ Panel B. Regressions Results } \\
\hline \multirow{2}{*}{ Regression } & & & $R^{2}$ & \\
\hline & $\gamma_{0}$ & $\gamma_{1}$ & $\%$ & F-Statistic \\
\hline $\begin{array}{l}1 \\
(N=20)\end{array}$ & $\begin{array}{r}0.0910 \\
(15.05)^{* *}\end{array}$ & $\begin{array}{r}0.0707 \\
(11.50)^{* *}\end{array}$ & 88.03 & $132.34^{* *}$ \\
\hline
\end{tabular}

**Significant at the 0.01 level. 
The risk-return relation is tested by regressing the average portfolio betas on annualized average portfolio returns. The results reported in Panel B of Table 6 provide strong evidence that investors are paid for holding beta risk. Changes in beta explain 88 percent of the variation in average portfolio returns. The estimated slope coefficient of $0.0707(t=11.50)$ indicates a market risk premium of 7.07 percent, and the intercept of $0.091(t=15.05)$ reflects a risk-free rate of 9.1 percent over the testing period, 1936-1990. ${ }^{10}$ These results strongly support the presence of a positive tradeoff between risk (beta) and return.

\section{Summary and Conclusion}

Previous studies testing for a systematic relationship between risk (as measured by beta) and returns find weak and intertemporally inconsistent results. These test results are biased due to the conditional relation between beta and realized returns. A positive relation is always predicted between beta and expected returns, but this relation is conditional on the market excess returns when realized returns are used for tests. In this study, a methodology that considers the positive relation between beta and returns during up markets and the negative relation during down markets is employed. This method yields the following findings:

i) a systematic relation exists between beta and returns for the total sample period and is consistent across subperiods and across months in a year, and

ii) a positive tradeoff between beta and average portfolio returns is observed.

Since the concerns regarding the weak correlation between beta and the crosssection of returns appear to be unfounded, the results support the continued use of beta as a measure of market risk.

\footnotetext{
${ }^{10}$ The market risk premium of 7.07 percent is consistent with the findings of Lakonishok and Shapiro (1984), who estimated the risk premium to be 7.7 percent annually.
} 


\section{References}

Chang, E., and M. Pinegar. "A Fundamental Study of the Seasonal Risk-Return Relationship: A Note." Journal of Finance, 46 (1988), 1035-1039.

Chen, N.; R. Roll; and S. Ross. "Economic Forces and the Stock Market." Journal of Business, 59 (1986), 383-404.

Fama, E. "Efficient Capital Markets: II." Journal of Finance, 46 (1991), 1575-1617.

Fama, E., and K. French. "The Cross-Section of Expected Stock Returns." Journal of Finance, 47 (1992), 427-465.

Fama, E., and J. MacBeth. "Risk, Return, and Equilibrium: Empirical Tests." Journal of Political Economy, 81 (1973), 607-636.

Lakonishok, J., and A. Shapiro. "Stock Returns, Beta, Variance and Size: An Empirical Analysis." Financial Analysts Journal, 40 (1984), 36-41.

"Systematic Risk, Total Risk and Size as Determinants of Stock Market Returns.” Journal of Banking and Finance, 10 (1986), 115-132.

Reinganum, M. "A New Empirical Perspective on the CAPM." Journal of Financial and Quantitative Analysis, 16 (1981), 439-462.

"The Anomalous Stock Market Behavior of Small Firms in January: Empirical Tests for Tax-Loss Selling Effects.” Journal of Financial Economics, 12 (1983), 89-104.

Roll, R., and S. Ross. "On the Cross-Sectional Relation between Expected Returns and Betas." Journal of Finance, 49 (1994), 101-121.

Rozeff, M., and W. Kinney. "Capital Market Seasonality: The Case of Stock Returns.” Journal of Financial Economics, 4 (1976), 379-402.

Schwert, G. "Size and Stock Returns, and other Empirical Regularities." Journal of Financial Economics, 12 (1983), 3-12.

Tinic, S., and R. West. "Risk and Return: January vs. the Rest of the Year." Journal of Financial Economics, 13 (1984), 561-574.

Wiggins, J. “Betas in Up and Down Markets.” Financial Review, 27 (1992), 107-124. 